Janapriya Journal of Interdisciplinary Studies, Vol. 6 (December 2017)

\title{
Research Article Application of Cost Reduction Tools in Manufacturing Organizations at Pokhara
}

\author{
Devilal Sharma, Lecturer, TU \\ Faculty of Management, Janapriya Multiple Campus \\ Email:dlshaema@gmail.com
}

\begin{abstract}
s
Today's business organization's success highly depends upon the satisfaction of customer needs and wants since it become the age of globalization. All the manufacturing organizations of Pokhara valley are needed to mass customize their product as the requirement of the customer and satisfy to their needs and wants. For this purpose, organizations have to use the modern technology. This study aims to evaluate the application of cost reduction tools in Nepalese manufacturing organizations with reference to Pokhara valley. Out of total manufacturing firm, only 10 organizations have been selected at least two samples from each stratum out of the target population. Primary data have been collected through the structured questionnaires by distributing it to the production manager or finance manager of the concerned organization. The information has been collected through unit visits. An empirical investigation has been conducted in order to find out various aspects of cost reduction tools. The major tool used for this purpose is the questionnaire. Nepalese manufacturing organizations are selecting the purchase of raw material, production planning and control as the area of reducing their cost. All of the organizations are conscious about TQM as the technique of cost reduction. Most of the organizations are applying product line rationalization, supply chain management, KAIZEN system, reengineering as the technique of cost reduction. Most of the organizations are not applying the Design for manufacturability and concurrent engineering, on demand lean production,
\end{abstract}


Application of Cost Reduction ...

build to order, part standardization, Just in Time production system as the tools of cost reduction.

Keywords: Application, cost reduction, Nepalese manufacturing industries, industrialization, cost reduction tools

\section{Introduction}

Extensive development of industry in a country is called industrialization. Nowadays many countries in the world have been industrialized. Industry produced goods of various kinds and supplies them to the consumers. Every country in the world wants to extend its industry. Industrialization is the process of social and economic change that takes place along with technological innovation. Britain initiated industrialized textile making by using new technology that replaces the human labor. This was widely considered industrial revolution. The huge increase in productivity was possible from Britain's imported raw cotton that stood at 1000 tons in 1760 and 222000 tons in 1850 (www.journals.cambridge.org). Before the world war-II, Nepal had basic industries like curio, bricks, tiles, biscuits, confectionaries and so on. The early years of Nepal's industrial history were not very smooth. Policy contradictions, capital inadequacy and infrastructural difficulties posed major constraints. This difficulty still continues. Technically, Nepal's industrialization process began 75 years ago when Udyog Parishad was constituted in 1935 and company act was enacted in 1937 with the aim to promote and protect the agriculture, industry and commerce. Nepal's industrialization process got momentum from 1936, the year when Indian capital began to flow into Nepal to take advantages of the available cheap raw materials and labour. Indians considered they were relatively sage here from India's complicated custom and tax law under the British rule. The company act provided for the incorporation of industrial enterprises, a joint stock principle with limited liability. As a result, the first prominent Indian businessmen Radha Krishna Chamaria, from a well known family of Marwari financiers from Kolkotta, 
Janapriya Journal of Interdisciplinary Studies, Vol. 6 (December 2017)

assisted establishing Biratnagar jute mill as a collaborative venture of India and Nepali entrepreneurs with initial capital of 1,60,000 Indian rupees.

The manufacturing sector posted a decline in terms of per capita growth in the last decade, a government report has shown. Among the sectors contributing to the national economy, manufacturing was the only sector that saw the decline over the period. The sector saw a decline of 0.2 percent per capita from 2000-01 to 2012-13, the period marked by the Maoist insurgency, political instability, power crisis and labor problems. Besides the decline in per capita growth, the sector's contribution to the gross domestic product (GDP) fell to 6.2 percent in 2012-13 from 9 percent In fiscal year 2000-01, according to the report titled "Development of Manufacturing Industries in Nepal: Current State and Future Challenges" released by the Central Bureau of Statistics (CBS).Manufacturing's contribution to the GDP in Nepal is the lowest compared to a few other select countries of the South Asian region, with Bangladesh having the highest contribution of 17.6 percent.

Industrial development in Nepal is at an initial stage with all types of manufacturing industries, contribution for not more than 15.1 percent of the Gross Domestic Product (GDP), while contribution of service and agriculture sector to the GDP remains 53.2 percent and 31.7 percent respectively (www.indexmundi.com/nepalgdp-composition-by-secter). However, small and medium enterprises (SME'S) overwhelmingly dominate the industrial sector of Nepal. It plays a major role as sources of employment in the manufacturing sector and significantly contributes to value addition and export trade of the country.

Cost reduction may be defined as an attempt to bring cost down. Cost reduction implies real and permanent reduction in the unit cost of goods manufactured or services rendered without impairing their product suitability for the use intended. The goal of cost reduction is achieved in two ways: i) by reducing the cost per unit and b) by increasing productivity. The steps for cost reduction include elimination of waste, improving operation, increasing productivity search for cheaper materials, improved 
Application of Cost Reduction ...

standards of quality finding other means to reduce costs (Lal; 1996; 1077).

The term cost reduction denotes real or genuine savings in production, administration, selling and distribution costs brought about by the elimination of wasteful and inessential elements from the design of the product and from the techniques and practices carried out in connection therewith. The necessity for cost reduction arises when profit margin has to be increased without an increase in the sales turnover i.e. for the same volume of sales, the cost of sales should be reduced (Ojha \& Gautam, 2008:147).

Evidence has shown in diary industries toward cost reduction that the organization could not found to use the ABM, Build to order, Mass customization, Quality Control techniques of cost reduction (Nepal, 2005). Regarding the application of cost reduction tools, the main reason behind less use to JIT in Nepalese manufacturing organization is the lack of information about JIT, and non-availability of suppliers. There is the lack of skilled manpower and internal failure in applying TQM. The main cause of not applying benchmarking is lack of proper direction and co-ordination. The constraint cause of ABM is poor organization culture. The companies are trying to achieve objective by means of increasing selling price. In order to make success of the system properly, Nepalese manufacturing companies should establish the long term stable relationship with the employees (KC, 2009). An attempt to reduce individual costs in one may be offset by increased costs in other areas, a trade off situation. Increased cost in one area can be motivated if the total cots decrease. In the case for ABB a centralized distribution model will reduce the costs in all areas. Hence, a centralized distribution model will decrease and increase the service level for ABB. The total logistics costs can be reduced by almost 28 percent using a distribution centre (Forderberg, 2010). Majority of the organizations are not using the JIT Production System, ABM, TQM tools for cost reduction (Sharma, 2011).

The contribution to the cost reduction in the automobile industry can provide a coherent framework for companies' management teams with 
Janapriya Journal of Interdisciplinary Studies, Vol. 6 (December 2017)

some ideas to reduce cost. Video-interviews have been used with two managers from SVW and GAC Toyota. These five costs can be solved by planning the best route, the method of economic order quantity, the method of activity based classification and just-in-time. The Materials are factors to help automobile companies reduce costs in the production sectors. Standardization of materials and improvement of productivity have been provided, the effective implementation of those two measures can help automobile companies reduce production costs directly in the Chinese automobile market (Zhiran \& Menxiao, 2012).

About $80 \%$ of all cost reductions are caused due to direct improvements related to the development of offshore wind farms. This is mainly due to the fact that the wind turbine contributes a relatively large part of the investment costs and that cost reductions may be only 40-60\% compared to current investment costs. Main reason behind this large cost reduction is the assumed mutual learning of onshore and offshore wind turbines with increasing diffusion. The remaining $20 \%$ of total cost reductions are caused by autonomous developments. Most important are the development of steel prices, as this directly affects the foundation structures and towers. Finally, the long-term stable offshore prospects may support cost reductions. No single country has the potential to satisfy this need over an extended period of time. Thus, a policy recommendation is to consider a joint European policy regarding the stimulation of offshore wind might be a great benefit both to ensure offshore wind diffusion and cost reduction (Junginger \& Faaij, 2013). In manufacturing unit, where its main cost element is the material cost. Manufacturing companies are preferring techniques like value engineering, quality control, budgetary control, for the purpose of cost reduction. This technique fulfills the objective of company i.e. "Low Cost Manufacturer" (Barbole, Nalwade \& Parakh, 2013).

Corporate profitability, which is conventionally considered to be a function of cost, capital employment, revenues and customer service, is now much a function of effective supply chain management as well. The concept is encompassing the strategies of procurement, quality control, extensive use 
Application of Cost Reduction ...

of global sourcing along with human training and management leading to the concept of value added management (Patil, 2014). There are worth investing more attention in to the procurement policy, both order quantities and reorder points. This is for trying to reduce total supply chain costs related to purchase costs and inventory carrying costs. It is proven that there are possible savings for putting more attention to articles from suppliers. Optimizing these values is considered for a short term period a good solution for trying to reduce total supply chain costs for spare parts from supplier to buyer (Glide, 2015).

There are many problems which are faced by the Nepalese manufacturing organization in Nepal. They are related with political interference, lack of finance, small market, lack of mutual trust, lack of efficiency of manpower, lack of technical knowledge, labor problems, lack of infrastructure etc. Likewise over capitalization, bureaucratic system prone to corruption, long time consumption for decision making, political interference and excessive control have discouraged the private sector and hurt public sentiments or confidence. Frequent changes in government and their policies have gained less confidence and expectation of the private sector. Hence, Nepal has been considered to be the country with limited level of investment climate.

In this context, the research work intends to what extent do Nepalese manufacturing organizations with reference to Pokhara valley apply cost reduction tools? The main objective of the study is to evaluate the application of cost reduction tools in Nepalese manufacturing organizations with reference to Pokhara valley.

\section{Data and Methods}

All together the 264 manufacturing organizations established and operating in Pokhara valley (www.doind.gov.np/ind-stat-2070/71) have been taken as population of the research study. Due to the limitation of cost and time, only 10 organizations have been selected, at least two samples from each stratum out of the target population. The samples have been stratified as 
Janapriya Journal of Interdisciplinary Studies, Vol. 6 (December 2017)

three industries from food industries, viz. Him Shree foods (Pvt.) Ltd., Pokhara, Pokhara Noodles (Pvt.) Ltd., Pokhara and Karmacharya Bakes and Foods, Pokhara. Similarly two paper industries such as Global Saikshik Samagri Kendra, Industrial State, Pokhara and Nawa Durga recycling (Pvt.) Ltd., Industrial State. On the other hand, three from Gas, Polypipe and plastic product industries such as Shakti Gas Industries, Pokhara, Grihalaxmi Gas Co. (Pvt.) Ltd., Pokhara and Jaya Packaging (Pvt.) Ltd., Industrial State, Pokhara and of two diary industries Fishtail Dairy (Pvt.) Ltd., Pokhara and Sujal Dairy (Pvt.) Ltd., Industrial State, Pokhara.

For this study, primary data have been collected through the structured questionnaires consisting of 27 multiple choice questions by distributing it to the production manager or finance manager of the concerned organization. The information has been collected through unit visits. An empirical investigation has been conducted in order to find out various aspects of cost reduction tools. The major tool used for this purpose is the questionnaire. A total 15 set of questionnaires were distributed to the sample manufacturing organizations, but only 10 sets of questionnaire were returned back from these organizations. The collected information has been tabulated in a frequency distribution for the purpose of data presentation, analysis and extract of findings. As the respondents are given opportunities for giving more than just one answers to the questions, the column total reflects sampled organizations from each subsectors and the row total shows the total number of organizations choosing a particular answer. For the analysis of data, percentage analysis method has been adopted.

\section{Results and Discussion}

A survey was conducted over ten manufacturing organizations in Pokhara valley to explore about how they are trying to utilize the cost reduction tools as a means of profit maximization. Response toward widely used ten different tools of cost reduction was examined and tried to analyze here. There are many areas which are required to apply in the cost reduction program. A survey was conducted to gather information about areas on 
Application of Cost Reduction ...

which organizations are suffering from cost related problem and applying cost reduction program. The study revealed the following results:

Table 1

Areas Selected for Cost Reduction

\begin{tabular}{|c|c|c|c|c|c|c|}
\hline \multirow[b]{2}{*}{ Particulars } & \multirow{2}{*}{$\begin{array}{c}\text { Food } \\
\text { industries }\end{array}$} & \multirow{2}{*}{$\begin{array}{c}\text { Paper } \\
\text { industries }\end{array}$} & \multirow{2}{*}{$\begin{array}{c}\text { Gas, } \\
\text { Polypipe and } \\
\text { plastic } \\
\text { industries }\end{array}$} & \multirow{2}{*}{$\begin{array}{c}\text { Dairy } \\
\text { industries }\end{array}$} & \multicolumn{2}{|c|}{ Total } \\
\hline & & & & & No & $\%$ \\
\hline Product design & 0 & 0 & 1 & 0 & 1 & 10 \\
\hline $\begin{array}{l}\text { Production } \\
\text { planning \& control }\end{array}$ & 1 & 2 & 0 & 0 & 3 & 30 \\
\hline $\begin{array}{l}\text { Equipment and } \\
\text { plant layout }\end{array}$ & 0 & 0 & 1 & 0 & 1 & 10 \\
\hline $\begin{array}{l}\text { Selling and } \\
\text { distribution }\end{array}$ & 1 & 0 & 0 & 0 & 1 & 10 \\
\hline $\begin{array}{l}\text { Purchase of } \\
\text { material and } \\
\text { control }\end{array}$ & 1 & 0 & 1 & 2 & 4 & 40 \\
\hline Total & 3 & 2 & 3 & 2 & 10 & 100 \\
\hline
\end{tabular}

Source: Field survey, 2016

The result shows that most of the manufacturing organizations have selected the purchase of raw material and control as the area of cost reduction. $40 \%$ of the organization out of sampled have favored the purchase of raw material in lower price as the cost reduction program. Similarly, 30\% organizations have considered the production planning and control as the cost reduction program. Likewise, $10 \%$ favored the product design, $10 \%$ favored the equipment and plant layout, while $10 \%$ favored the selling and distribution as the area of cost reduction from which price of the product can be lowered. From the above result, it can be said that no organization gives priority for product design as the area of cost reduction. 
Janapriya Journal of Interdisciplinary Studies, Vol. 6 (December 2017)

Most of the organizations give more emphasis on purchase of raw material and control as the cost reduction areas.

As described earlier, there are various types of cost reduction tools, which are using by Japanese manufacturing organizations at present. This study deals whether Nepalese manufacturing organizations are applying the cost reduction program or not. If they are not applying such tools then it reveals the causes of higher cost.

\section{Table 2}

List of Manufacturing Firms Applying and Not Applying Cost

\section{Reduction Tools}

\begin{tabular}{|c|c|c|c|c|c|c|}
\hline \multirow[t]{2}{*}{ Cost Reduction Tools } & \multicolumn{2}{|c|}{ Applying } & \multicolumn{2}{|c|}{ Not Applying } & \multicolumn{2}{|c|}{ Total } \\
\hline & No. & $\%$ & No. & $\%$ & No. & $\%$ \\
\hline$\overline{D F M} \& \mathrm{CE}$ & 4 & 40 & 6 & 60 & 10 & 100 \\
\hline On Demand Lean Production & 3 & 30 & 7 & 70 & 10 & 100 \\
\hline Build to Order & 2 & 20 & 8 & 80 & 10 & 100 \\
\hline Mass-customization & 0 & 0 & 10 & 100 & 10 & 100 \\
\hline Part Standardization & 4 & 40 & 6 & 60 & 10 & 100 \\
\hline Product Line Rationalization & 7 & 70 & 3 & 30 & 10 & 100 \\
\hline Supply Chain Management & 8 & 80 & 2 & 20 & 10 & 100 \\
\hline Total Quality Management & 10 & 100 & 0 & 0 & 10 & 100 \\
\hline KAIZEN System & 8 & 80 & 2 & 20 & 10 & 100 \\
\hline JIT Production System & 1 & 10 & 9 & 90 & 10 & 100 \\
\hline Reengineering & 8 & 80 & 2 & 20 & 10 & 100 \\
\hline
\end{tabular}

Source: Field Survey, 2016

The data reveals that only $40 \%$ organizations are using the Design for manufacturability and concurrent engineering (DFM \& CE) as the cost reduction tool, while $60 \%$ organizations are not adopting this tool for reducing cost. The above data reveals that $30 \%$ organizations are applying on demand lean production and $70 \%$ organization out of sampled are not 
Application of Cost Reduction ...

adopting this tool as the cost reduction. Similarly $20 \%$ of the organizations out of sampled organizations are using Build to order as cost reduction tool, while $80 \%$ of the organizations are not applying this tool as the cost reduction. From the above data only $40 \%$ of the organizations are using the standardized parts, while $60 \%$ of the sampled organizations are using the varieties of parts. From the above data, only $70 \%$ of the manufacturing organization are using the product line rationalization as the technique of cost reduction, while $30 \%$ organization out of sampled organization are not applying this technique due to different reasons such as due to the fear of losing customer, due to the fear of decreasing sales volume etc. Furthermore, it can be seen that $80 \%$ of the sampled organizations are managing their supply chain as the cost reduction tool, while $20 \%$ of the sampled organization could not applying the supply chain management technique. Moreover, all of the sampled Nepalese manufacturing organizations are applying the Total quality management as the cost reduction tool. In addition, it can be seen that $80 \%$ of the sampled organizations are continuously improving their organization by solving problem step by step, while $20 \%$ of the sampled organization are not adopting the KAIZEN system to improve their organization. Table 2 shows that only the $10 \%$ of the sampled organizations are applying the Just in Time production system as the cost reduction tool, while $90 \%$ of the sampled organizations are not applying this technique as cost reduction tool. Furthermore, it can be seen that most of the organizations are applying the Reengineering business process as the technique of cost reduction. $80 \%$ of the sampled organizations are applying the Reengineering technique as the cost reduction tool, while 20 percent of the sampled organizations are not applying this tool for the reduction of cost. The above table shows that $100 \%$ of the sampled organizations think that there is necessity of applying cost reduction tools to compete in the global market, but there is lack of managerial, technical manpower, lack of knowledge about the different cost reduction tools, lack of modern technology etc, which may restrict in the application of this technique. 
Janapriya Journal of Interdisciplinary Studies, Vol. 6 (December 2017)

In this ground most of the manufacturing industries based on Pokhara valley has not been adopting and applying the cost reduction tools. What are the causes due to them are not permitted to apply the tools? The study tries to identify the causes for not applying the tools as

\section{Table 3}

Causes of not Applying the Cost Reduction Tools

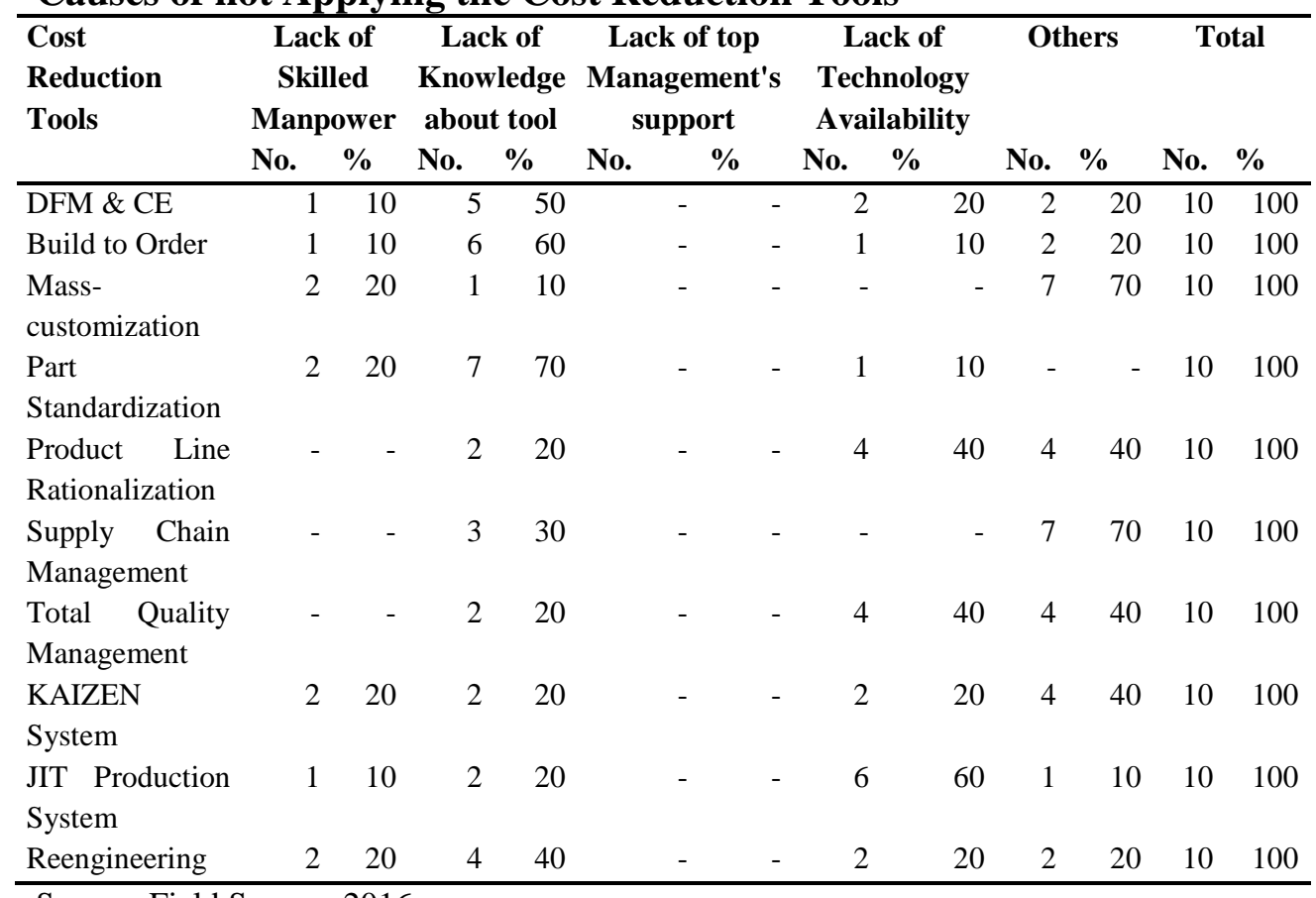

Source: Field Survey, 2016

Note: Others include fear of revenue loss due to decrease is sales, non availability of supplies and fair environment, fear of losing market share.

From table 3 it can be said that the main practical difficulty in applying the Design for Manufacturability and Concurrent Engineering as the cost reduction tool is lack of information about this tool. 5 manufacturing organization out of 10 sampled organizations, which are not using the DFM and $\mathrm{CE}$ due to lack of knowledge and information about this cost reduction tool. Two out of 10 not uses it due to lack of technology, two due to other reasons and one manufacturing organization not adopting DFM and CE due 
Application of Cost Reduction ...

to the lack of skilled manpower. Further, it can be seen that $60 \%$ of the organization out of the sampled which are not using the Build to order as the cost reduction tool due to non availability knowledge regarding the tool. $20 \%$ organization out of sampled are not applying build to order due to other reasons and $10 \%$ each due to lack of skilled and technical manpower, and availability of technology. Moreover, it can be said that most of the organizations are not using the standardized parts due to the lack of suppliers supplying standardized parts. about $70 \%$ organizations out of sampled which are not using standardized parts due to the lack of suppliers supplying standardized parts, while $20 \%$ organization are not using the standardized parts due to the lack of knowledge and $10 \%$ due to other reason about the part standardization. From table above it can be seen that $40 \%$ due to not availability of technology, $40 \%$ due to other reasons and $20 \%$ due to lack of knowledge regarding the tool organizations which are not applying product line rationalization technique as the cost reduction tool. However, it can be seen that $50 \%$ of sampled organizations are not using supply chain management due to the lack of suppliers for spontaneous supply chain, while $70 \%$ organizations are not applying supply chain management as the cost reduction tool due other reasons and $30 \%$ due to the lack of knowledge about supply chain management. From the data presented above, it can be seen that $40 \%$ organizations are not applying due to other reasons where as $20 \%$ due to lack of technical manpower and $20 \%$ due to lack of knowledge about the KAIZEN system. Moreover, it can be said that most of the sampled organizations which are not applying Just in Time production system due to lack of modern technology. $60 \%$ of the sampled organizations are not applying this tool due to lack of modern technology, while $20 \%$ organizations are not using this technique due to the lack of knowledge about just in time production system. Likewise, $10 \%$ sampled organizations are not applying Just in Time production system due to lack of knowledge about JIT and $10 \%$ due to other reasons. From the above table it is cleared that $40 \%$ of the organization which are not applying Business process Reengineering is due to lack of knowledge about the Business process Reengineering, where as 
Janapriya Journal of Interdisciplinary Studies, Vol. 6 (December 2017)

$20 \%$ due to lack of skilled manpower, $20 \%$ due to lack of technology and

$20 \%$ due to other reasons. No one sampled organizations not applying anyone tools of cost reduction due to lack of top management's support. Thus, it is cleared that the industrialists and executives are highly committed to adopt the cost reduction tools in the Nepalese manufacturing sectors.

\section{Conclusions}

After conducting this research work on the topic of cost reduction tools used in Nepalese manufacturing organization, it can be concluded that, Most of the organizations located in Pokhara valley are not applying the design for manufacturability and concurrent engineering as the tool of cost reduction due to the lack of knowledge about the tools. Most of the organizations are not applying the on demand lean production system as the cost reduction tools. Most of the organizations based in Pokhara valley are not applying the build to order as the cost reduction tool. No one of the organizations is applying the mass customization as the cost reduction tool due to the lack of modern technology. Most of the organizations of Pokhara valley are not applying part standardization as the technique of cost reduction. It can be concluded that most of the organizations of Pokhara valley prefer the product line rationalization as the cost reduction technique. Furthermore, it can be concluded that almost of the organizations of Pokhara valley are using the Total quality management as the technique of cost reduction. It is also concluded that most of the organizations are not applying the Just in time production system as the tool of cost reduction. Most of the manufacturing organizations established in Pokhara valley are applying the KAIZEN system and Business Process Reengineering as the technique of cost reduction tool. Most of the Nepalese manufacturing organizations are selecting the purchase of raw material, production planning and control as the area of reducing their cost. All of the organizations are conscious about TQM as the technique of cost reduction. Most of the organizations are applying product line rationalization, supply chain management, KAIZEN system, reengineering 
Application of Cost Reduction ...

as the technique of cost reduction. Most of the organizations are not applying the Design for manufacturability and concurrent engineering, on demand lean production, build to order, part standardization, Just in Time production system as the tools of cost reduction.

\section{References}

Barbole, A.N., Nalwade, Yubraj, D. and Parakh, D. (2013). Impact of cost control and cost reduction techniques on manufacturing sector. www.isrj.net.

Froderberg, A. (2010). Cutting logistics costs with a centralized distribution model for ABB's distribution of $L V$ products in Asia Pacific. lulea university of technology, Singapore, www.epubl.itu.se/ltu-ex-06217-se.

Glide, Didrik (2015). Possibilities for cost reduction in spare part logistics, a case study for Hustadmarmor.

Junginger, M. \& Faaij, A. (2013). The research on cost reduction prospects for the offshore wind energy sector. www.journals.sagepub.com.

K.C. Hari Bahadur (2009). A Survey Study on An Application of Cost Reduction Tools Used in Nepalese Manufacturing Organizations. An Unpublished Master's Dissertation, Tribhuwan University, Nepal

Lal, J. (1996). Managerial Accounting. Delhi: Himalaya Publishing House.

Nepal, R. (2005). An application of cost reduction tools: A case study in Dairy Development Corporation. An Unpublished Master's Dissertation, Tribhuwan University Nepal

Ojha, K. \& Gautam, A. (2008). Profit Planning and Control. Kathmandu: Asmita Books Publisher and Distributor (Pvt.) Ltd.

Patil, R.N. (2014). Supply chain management for corporate profitability through distribution of product and competitive advantage. www.bvucoepune.edu.in.

Sharma, K. (2011). An application of cost reduction tools: A survey study in Nepalese manufacturing organizations with reference to Kathmandu valley. An Unpublished Master's Dissertation Tribhuwan University, Nepal 
Janapriya Journal of Interdisciplinary Studies, Vol. 6 (December 2017)

Wolf, Howard K. \& Pant, P. R. (2005). Social Science Research \& Thesis Writing. Kathmandu: Buddha Academic Publishers and Distributers Pvt. Ltd.

Zhiran, Xu \& Mengxiao, Z. (2012). Cost reduction in the automobile industry, case studies of the Chinese market. www.diva-portal.org. 